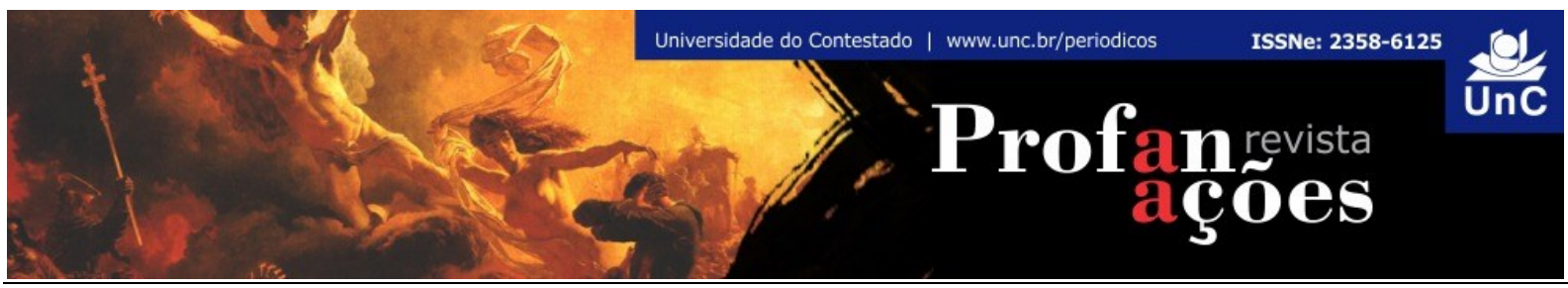

\title{
O QUE PODE UM CORPO? ESPINOSA E DELEUZE, O DESEJO COMO PRODUÇÃO
}

Sarah Bernadette de Carvalho Alcantara ${ }^{1}$

\begin{abstract}
RESUMO
O tema deste artigo se concentra no conceito de "desejo" entendido como "produção". Este conceito é introduzido por Gilles Deleuze a partir de sua leitura do pensamento de Espinosa. Neste sentido, o presente estudo se volta justamente sobre a questão de Espinosa: "o que pode um Corpo?" Ou seja, qual a potência de um corpo? O pensar deleuziano transita transformando a relação entre sujeito e objeto, de tal forma que o conceito de desejo se liberta da falta como elemento central e necessário para começar a ser compreendido como um campo de produção. Assim sendo, a pesquisa analisa o deslocamento conceitual deleuziano que visa ir além da linguagem usual, focada na identidade do sujeito desejante, para estabelecer uma lógica em que o acontecimento atravessa e muda este próprio sujeito, onde o ser dá lugar ao devir e a relação com uma falta originária é substituída pelo campo de produção. Sob estes novos parâmetros conceituais, o trabalho expõe como com a filosofia de Deleuze é possível abandonar a noção de um sujeito atrelado à sua imagem no outro para começar a compreendê-lo como uma relação de multiplicidade produtora em si mesma. As questões a serem abordadas se desdobram da seguinte maneira: investigar quanto ao significado de Produção em Deleuze, fundamentar quanto à filosofia de Espinosa sobre a potência de agir e estabelecer a relação entre a filosofia da diferença de Deleuze e a filosofia Espinosiana, ambas construtoras de um conceito de desejo livre da representação e do negativismo.
\end{abstract}

Palavras-chave: Deleuze. Espinosa. Desejo. Produção.

\footnotetext{
1Doutoranda em Filosofia pela PUC/PR, Mestre em Filosofia pela PUCPR (2016). Professora do curso de Medicina da Universidade do Contestado. Pontifícia Universidade Católica do Paraná (PUCPR). Paraná. Brasil. E-mail: sarahb.alcantara@hotmail.com
} 


\begin{abstract}
The theme of this work focuses on the concept of desire as production introduced by Deleuze and in the inspiring thinking of Spinoza regarding this concept. Deleuze's philosophy is a philosophy where the action moves at a bookie movement, transforming the relationship between subject and object in such a way that the concept of desire is liberated from the fault and generates production. At the time proposed to go beyond the usual language that focuses on the identity of the subject, setting it to labels, establishing a logic where the action goes through changes and this guy, where he gives way to becoming, and the relationship of lack produced by the desire disappears, because there is no longer the subject and its image on the other, but between ourselves and that produced movement. The concept of desire as production is found in Deleuze active part in the construction of a Philosophy of Difference, with this study we propose a reflection on the elements that make up this thought, and on the motivational aspects of the philosophy of Spinoza where Deleuze is among other concepts, the power in a totally free from the processes of representation immanent plan. Our study is geared towards the question of Spinoza that inspires Deleuze: "what can a body do?" That is, what the power of a body? Examine the construction of the concept of desire as production, Deleuze's philosophy and its intersections with the philosophy of Spinoza, is the goal of this study, which unfolds in the following questions: To investigate as to the meaning Production in Deleuze, substantiate as to philosophy Espinosa on the power to act and establish the relationship between the philosophy of Deleuze difference, and Espinosiana philosophy, both construction of a concept of free will and the representation of negativism.
\end{abstract}

Keywords: Deleuze. Espinosa. Desire. Production.

\title{
INTRODUÇÃO
}

Estudar o conceito de desejo como produção na filosofia de Gilles Deleuze e suas intersecções com a filosofia de Espinosa, é o objetivo geral deste trabalho. Para conquistá-lo, questões específicas que se desdobram, no decorrer deste artigo, serão abordadas. Entre elas, se destaca a investigação quanto ao significado do conceito de produção em Deleuze.

Uma das consequências interrogativas centrais na questão da produção é se esta implicaria, necessariamente, numa negatividade permeada pela falta? Para responder esta questão, se torna necessária a leitura do resgate da pura diferença feito por Deleuze, quando estabelece uma rota do pensamento acompanhada por noções que colocam o ser como imanente, ou seja, onde toda a questão da transcendência, que qualifica o sujeito, é substituída pela expressão da univocidade. 
O primeiro ponto a ser abordado, portanto, se propõe a trafegar por este caminho, que estabelece a possibilidade de uma filosofia da diferença. Tal filosofia transita por um movimento agenciador transformando a relação sujeito e objeto de tal forma, que o conceito de desejo liberta-se da falta e gera produção. Ou seja, no momento em que propõe ir além da linguagem usual, aquela que foca a identidade do sujeito fixando-o através de predicados ou categorias, Deleuze estabelece uma lógica onde a ação atravessa e muda este sujeito. O ser dá lugar ao devir e a relação da falta produzida pelo desejo desaparece, pois não existe mais o sujeito e sua imagem no outro, e sim, o espaço produzido, o "entre", que se estabeleceu e produziu movimento.

O conceito de desejo como produção encontrado em Deleuze constitui parte ativa na construção da sua Filosofia da Diferença. Esta pesquisa propõe a reflexão sobre os elementos que compõe este pensamento, bem como, sobre os aspectos inspiradores da filosofia de Espinosa, na qual Deleuze encontra, entre outros conceitos, o de potência em um plano imanente totalmente liberto dos processos da representação abordados no desenrolar deste estudo.

$\mathrm{Na}$ evolução histórica do pensamento filosófico descrita por Larrauri (2006), inscreve-se o sujeito do conhecimento separando a razão do instinto, o homem do resto da natureza, a alma do corpo, o espírito da matéria e a moral da vida. Descartes introduz este pensamento com sua concepção do Homem Robô, cuja natureza funciona mecanicamente. Desta separação, resulta um homem sujeito às forças externas, no qual a liberdade criativa é discutível, a não ser pela existência acorporal do espírito. Esse estudo se volta justamente sobre a questão de Espinosa que inspira Deleuze: “o que pode um Corpo?”, ou seja, qual a potência de um corpo? (DELEUZE, 1998) A partir desta questão reafirmamos que o caminho central é o estudo sobre o desejo que se entrelaça além da linguagem, pelo poder do corpo, o que abriria a passagem de uma ontologia de poder para uma ontologia de potência (MIQUEU, 2009). Nesta, conforme Deleuze (1998), o desejo não está ligado à lei, não se define por nenhuma falta essencial, e sim, pela produção.

Finalizando, objetivamos demonstrar como esta noção de diferença como produção não negativa irriga a noção de desejo como produção. Iniciamos abordando este conceito de desejo, reconhecendo-o em um dos pontos integrantes da filosofia da diferença. O mesmo foi inaugurado por Deleuze, especificamente, 
quando escreveu com Guattari o "Anti-Édipo"2, no entanto, suas primeiras obras já continham esse pensamento que anunciava uma proposta independente das representações submersas às identidades. O filósofo pensa o desejo como um trabalho do inconsciente concebido em agenciamento de territórios. Deleuze amplia o conceito de desejo além das relações edipianas traduzidas na cena familiar, regidas em nome do pai, para um desejo inscrito em nome da história, produtivo na imanência das máquinas desejantes e nas grandes máquinas sociais (ROUDINESCO, 2007).

Para Deleuze o desejo é algo construído e agenciado, é um operador efetivo que se confunde com as variáveis de um agenciamento. Os agenciamentos são movimentos horizontais que transitam por uma linha abstrata de vizinhanças, estas sem territórios fixos e sim móveis em suas singularidades.

As noções descritas no desenrolar do texto, implicam em uma questão própria sobre o que é um corpo para Deleuze e para Espinosa. Sabemos que para as mais diversas escolas, o corpo corresponde ao substrato, implicando em predicados e acidentes. Para os dois filósofos em questão, este corpo é acontecimento, ou seja, se define pelo quanto é capaz de afetar e ser afetado e existe na medida de seu encontro com outro corpo. Neste processo em que o corpo ontologicamente unívoco se define na multiplicidade dos encontros, a produção do desejo é o acontecimento. Neste, a inexistência de uma organização ditada em determinações o faz livre dos contornos, totalmente aberto à possibilidade de um "devir" revolucionário.

\section{UMA FILOSOFIA DA DIFERENÇA}

De modo geral, podemos indicar que Deleuze, ao situar a questão da diferença como elemento central de sua filosofia, se distancia da tradição do idêntico, ou seja, de todo processo da representação, que classifica o ser em categorias analógicas. Para Deleuze, a diferença existe e se manifesta no espaço da repetição; não é limitada por um sistema comparativo, pois comparar significa representar, identificar; e, assim, uma ideia de generalidade funcionaria como meio limitante. Pelo contrário, o que Deleuze pensa vai além de generalidades; ele pensa 2 O “Anti-Édipo": Obra escrita em 1972 pelo filósofo Gilles Deleuze e pelo psicanalista Félix Guattari.
Contém o pensamento destes dois autores sobre uma nova teoria do desejo. 
na singular possibilidade, do encontro, do entre que se estabelece, que destrói a necessidade da imagem de um sobre a ausência do outro, abrindo espaço para o existir de todos em inúmeras repetições, expressas em singulares diferenças.

Antes de desenvolver a questão a respeito da relação entre produção não negativa e diferença, propomos um olhar sobre a diferença em si, desvendada por Deleuze. Este momento do texto chama a atenção sobre uma possibilidade a respeito do pensamento do filosofo francês, isto é, de que sua filosofia, como um todo, invoque uma pragmática, uma práxis. Esta práxis se edifica sobre uma estrutura ontológica, através da qual sua compreensão se faz viável, ou seja, uma delicada cartografia conceitual que sustenta a possibilidade do acontecimento. Dentro desta, circula o conceito de diferença, ligado intimamente ao de univocidade e imanência, onde qualquer campo de transcendência inexiste, portanto, tudo que invoque um inatingível objetivo, gerador de uma eterna falta é abolido

Para Deleuze, não existem distinções valorativas em termos ontológicos, entre os entes "Não há hierarquia no existente"3, o fato de existir já fornece um estatuto ontológico equivalente e unívoco. Portanto, não há transcendência, pois há uma univocidade que já existe. Este ponto poderia gerar a seguinte questão: como o que não é qualificado, como o tudo, sendo idêntico, não se transforma em massa amorfa? A resposta poderia ser entoada através da seguinte perspectiva: não é massa amorfa porque é pura diferença. A univocidade é operada por uma diferença interna. Portanto, como nos fala Deleuze (2009), a igualdade do ser está presente em todas as coisas, sem mediações, no entanto, as coisas se mantêm desigualmente neste ser igual.

É importante afirmar que para Deleuze a diferença não se inscreve no conceito geral, sob pena, de mantê-la mediatizada pela representação, tema que será abordado adiante. O que ressaltamos aqui é este aspecto dinâmico e singular que entende a diferença como acontecimento. Em conformidade ao pensamento do filósofo citamos raia (2003) quando comenta que a diferença é ela própria irreconhecível, uma vez que sempre é remetida a outra diferença. A diferença não é

\footnotetext{
${ }^{3}$ Expressão parafraseada da fala do Prof. Eladio Craia sobre Corpo sem Órgãos no $9^{\circ}$ Simpósio Internacional de Filosofia e Psicanálise realizado em 2014 na Universidade Federal do Espirito Santo em Vitória. Além da expressão citada, a ideia central da escrita deste subtítulo, foi inspirada nesta exposição.
} 
o fenômeno e sim o que o possibilita. É o que permite que a sensação se produza; ela não é explicada, mas, sim, implicada em sua intensidade pura e imensurável.

"Quando o fundo emerge à superfície, o rosto humano se decompõe neste espelho em que tanto o indeterminado quanto as determinações vêm confundir-se numa só determinação que 'estabelece' a diferença” (DELEUZE, 2009, p. 56).

Estabelecer a diferença livrando-a de seu "estado de maldição" parece ser, como ensina Deleuze, tarefa da Filosofia da Diferença. Ou seja, é sua função livrá-la do processo que a condena a não existir fora da representação, em seu elemento racional, dentro de um horizonte centralizado e fixo. Como esse movimento se processa no pensar de Deleuze? Para responder tal questão, recorre-se à linha de análise de Larrauri (2000), que explica de uma forma didática o desenrolar de um novo silogismo agora expresso, e não mais baseado no sujeito e, sim, nos predicados. A vida, segundo descreve a autora, é uma relação, não é algo que está nos sujeitos, mas alguma coisa que passa por eles. A vida é o que está no entre, no espaço construído, existindo sem a necessidade dos sujeitos individuais que a encarnem. A dificuldade em vê-la assim tem uma razão, que é a visão tradicional da filosofia fixada em uma matriz organizada em torno à identidade, dos contornos fixos, classificatórios, em grandes e pequenas escalas do gênero e das espécies. No entanto, segundo o que Larrauri observa em Deleuze, a importância não está nos processos de identidades classificatórias externas, mas está no que passa, trespassa, muda. A lógica da vida não é uma lógica do ser, mas do "vir a ser". E a diferença é esta intensidade imensurável, que, em pura potência, cria um novo movimento. Portanto, pensar a diferença é pensar o ser como acontecimento, este, liberto do processo analógico que o empobrece e o mediatiza em função de uma possível aceitação imposta pela razão. Um ser que é unívoco porque não suporta a qualificação ou a hierarquia, mas que funciona em singularidades atravessadas pela diferença.

Ao abrir o espaço para a continuidade, entendemos que um novo conceito se articula ao de "Diferença Pura", e este é o de Multiplicidade. Com ele podemos deixar mais clara a articulação feita entre o pensamento do ser sendo a diferença, e a vida que tão próxima da diferença, pertence ao vir-a-ser, não ao ser. Essa multiplicidade seria a única forma de o pensamento captar o movimento da diferenciação, e somente assim produzir além da mediatização. 
O seguinte entendimento se faz processual: o ser se faz univocidade, porque já no fato de existir impossibilita a qualificação hierárquica, abrindo-se ao plano de imanência. A pura diferença resgatada, ontologicamente, por Deleuze acontece e atravessa o ser, em seu total processo de expressão, ou seja, fora da mediatização construída pela razão representada. E o acontecimento se faz vida pelo ser que é diferença, por meio de um devir, incluído na teoria das multiplicidades.

\section{A DIFERENÇA COMO PRODUÇÃO NÃO NEGATIVA}

Dando continuidade ao estudo sobre a diferença como elemento que compõe a tessitura do pensamento filosófico de Deleuze, atentamos quanto aos conceitos de representação, identidade e negatividade, para que possamos entender o processo que destaca a relação entre diferença e produção não negativa. Conforme afirma Deleuze (2009) a diferença e a repetição tomam o lugar do idêntico e do negativo, da identidade e da contradição;

Compreender a diferença pensada em si mesma implica partir de um olhar sobre a representação e suas exigências. Em Diferença e Repetição, Deleuze (2009) expressa seu pensamento explorando primeiro a questão da submissão da diferença, relacionada, ora a um entendimento divino inacessível, ora a um aquéminfernal insondável para nós, ou seja, um oceano da dessemelhança, o que exclui totalmente a possibilidade da relação do diferente com o diferente, relação essa que tornaria a diferença em si pensável e não domada pelos princípios da razão, ou, como diz o autor, "submetida ao quádruplo cambão da representação: a identidade no conceito, a oposição no predicado, a analogia no juízo, a semelhança na percepção" (DELEUZE, 2009, p. 365). Desta forma, a diferença é mediatizada e representada para ser salva dentro do conceito geral. Este conceito supõe uma relação comparativa e externa, entre elementos fixados em identidade, analogia, oposição e semelhança. Os elementos citados vêm da matéria sendo, pois acidentais.

Uma questão pontual a ser entendida se refere a diferença específica e a diferença genérica ambas construtoras de um conceito geral. A primeira, especifica, apresenta uma série de características que a torna mediadora, entre as quais a de produtora, demonstrada na questão do gênero, já que ele não se divide em 
diferenças, mas é dividido por elas que nele produzem as espécies correspondentes. A especificidade desta diferença faz com que não represente um conceito universal, mas apenas um momento particular em que há conciliação com o conceito geral, um máximo inteiramente relativo. Segundo Deleuze (2009), aí está o princípio de uma confusão danosa para a filosofia de diferença, confundir o estabelecimento próprio da diferença com a inscrição da diferença no conceito em geral. Dessa visão resulta toda a subordinação da diferença à oposição, à analogia, à semelhança, aspectos esses da mediação. A diferença genérica, por sua vez, é distributiva e hierárquica. Portanto, a instância capaz de proporcionar o conceito aos sujeitos é o juízo, o qual tem duas funções determinadas: a distribuição que ele assegura com a partilha do conceito, e a hierarquização assegurada pela medida dos sujeitos. Uma corresponde ao senso comum e a outra ao bom senso, que em conjunto configuram a justiça. Enquanto a diferença específica toma a identidade como inscrição a diferença genérica se inscreve na analogia do juízo. As duas longe de poderem nos comunicar um sentido próprio da diferença. O estar fora desses princípios da razão torna a pura diferença não representativa, impossível de existir. Fazer com que a representação conquiste o obscuro, ou seja, vá além dos limites de seus fixados horizontes, consiste, segundo o mesmo autor, no maior esforço da filosofia, compreendendo assim os extremos em suas potências.

Deleuze pensa o conceito de diferença de tal forma, que não hesita em romper com a leitura tradicional, tão logo a entende em sua profundidade, sem a preocupação de integrar o infinitamente grande ou o infinitamente pequeno, assumindo a divergência e o descentramento. A singularidade dessa ideia tem, com certeza, um caminho percorrido, onde outros conceitos, como o de imanência e univocidade, foram articulados. O primeiro liberta o ser da sua relação com o inatingível gerador da eterna falta; o segundo fala de um movimento em que substrato e substância têm um sentido único, mas que, nessa acepção, dão lugar à diferença; e essa, em seu conceito mais puro, se afasta de um modelo de valorações, ou seja, de identidades absorvidas desde o platonismo, onde a máxima diferença revelada foi a cópia. Portanto, a diferença como produção não negativa encontra seu lugar no pensamento de Deleuze, porque, afastado da transcendente prática hierárquica, tão cara à metafisica, encontra um ser que se reflete na 
diferença em uma relação múltipla, onde devires são possíveis, sem que o negativo, oriundo do jogo representativo, precise existir.

Conforme Silva (2000) comenta, o limite de uma filosofia fundada na representação seria justamente o de não conseguir encontrar um conceito de diferença interna, e, sim, extrínseca aos termos diferenciados, entre conceitos, como um elemento mediatizado. A questão que se faz importante aqui é o quanto a analogia do ser pode sufocar sua singularidade e, com isso, deixar submersa toda a potência que vem da possibilidade do caos.

O mundo dos simulacros define uma existência não forjada por conceitos transcendentes, uma existência desejada como ela é e não submissa aos valores da representação. E o que define a representação? Segundo Deleuze (2009), o elemento da representação como razão tem quatro aspectos principais: a identidade na forma do conceito indeterminado, a analogia do juízo que diz respeito à relação entre os conceitos determináveis, a oposição do predicado nas relações de determinação no interior do conceito e a semelhança na percepção, no objeto determinado do próprio conceito. A diferença representa, portanto, um mal a ser "salvo"; para que possa ser pensada, é necessário representá-la e, para isso, relacioná-la às exigências do conceito em geral. Nesse ponto, segundo o autor, está o princípio de uma danosa confusão para toda a filosofia da diferença, pois se confunde o estabelecimento de um conceito próprio da diferença com a inscrição da diferença em um conceito geral, marcado pela identidade de um conceito indeterminado e de todos os aspectos da mediação citados acima.

O mundo da representação tem origens em pressupostos morais que, embora até possam ser esquecidos, nunca deixarão de agir sobre causa e consequência nessa cadeia, entre o fundamento e o fundado. Segundo o pensamento de Deleuze $^{4}$, a representação é o lugar do ilusório transcendental, expresso pelo pensamento, pelo sensível, pela ideia e pelo ser: o pensamento se recobre pela identidade, forjada em postulados, desnaturando sua gênese. Nessa identidade, a visão moral do mundo se prolonga e se representa afirmada como senso comum.

\footnotetext{
${ }^{4}$ Cf. DELEUZE, Gilles. Diferença e Repetição. Tradução de Luiz Orlandi e Roberto Machado. 2.ed. São Paulo: Ed. Graal, 2009, p. 368-369. Neste ponto, o autor explica como a diferença fica subordinada à representação sob suas quatro raízes: identidade, semelhança, oposição e analogia. Que correspondem ao pensamento, ao sensível, à ideia e ao ser. Cada um deles determina um nó ilusório a ser desfeito no resgate da pura diferença.
} 
Para que a diferença seja restaurada no pensamento, é preciso desfazer o nó que consiste em retratar a diferença sob a identidade do conceito. O sensível, referente à segunda ilusão, concerne à subordinação da diferença à semelhança, ou seja, tende a anular-se na qualidade que a recobre, ao mesmo tempo que o desigual tende a igualar-se na extensão em que ele se reparte. Restaurar a diferença na intensidade, tomada como ser do sensível, é desfazer o segundo nó que subordinava a diferença ao semelhante na percepção.

A ideia do negativo consiste em uma terceira ilusão, que subordina a diferença à forma da limitação e da oposição. Essas são jogos de superfície enquanto que a profundidade viva, a diagonal, é povoada de diferenças sem negação. Restaurar o diferencial na ideia e a diferença na afirmação que dele deriva é romper essa relação injusta que subordina a diferença ao negativo. A quarta ilusão, afirma ainda Deleuze (2009), é a subordinação da diferença à analogia do juízo. O ser é análogo em relação aos conceitos e predicados determinados, mantém com eles uma relação interior, adquirindo uma identidade do senso comum distributivo e de um bom senso ordinal. O indivíduo só é; e só é pensado como portador de diferenças, ao mesmo tempo que o próprio ser se reparte nas formas fixas dessa diferença, o que trai sua natureza e a natureza das próprias distribuições, nômades, não sedentárias, bem como a natureza da própria diferença individuante.

Quando Deleuze (2009) pensa a ideia de descentramento submetida à repetição do que diverge e descentra, ele lança um novo conceito de repetição. $O$ que diverge não pode ser substituído e esse é um ponto que diferencia a repetição da generalidade; essa segue componentes quantitativos e qualitativos, em ciclos onde as trocas e substituições dos termos podem ser feitos. A repetição se funda apenas no que não pode ser substituído; portanto diz respeito a uma singularidade, não permutável, insubstituível. Conforme o autor, "se a troca é o critério da generalidade, o roubo e o dom são os critérios da repetição" (DELEUZE, 2009, p. 21).

Entre a filosofia da diferença e a filosofia da representação, existe, portanto, o considerável afastamento permeado por elementos conceituais que emergem de um único ponto: a questão imanente da filosofia da diferença, que, se libertando dos conceitos fixos e analógicos, percebe o movimento unívoco e singular do ser, bem 
como toda potência oriunda de sua multiplicidade; ao passo que a filosofia da representação, em uma inércia de acomodação, se assegura do que não pode ser mudado, fazendo do limite o elemento controlador de todo movimento oriundo da divergência.

\section{POTÊNCIA EM ESPINOSA - O QUE PODE UM CORPO?}

Ao propormos a continuidade da reflexão sobre o desejo como produção, temos como fonte o encontro de Deleuze com Espinosa.

Para Espinosa, a potência se faz pelo encontro de corpos. Uma questão norteadora se faz presente: "O que pode um corpo?". Essa questão pressupõe outra: qual a estrutura do corpo, como se articula? Em uma tentativa de aprofundálas, trabalha-se o texto de Deleuze (1968): "Espinosa e o problema da Expressão". A estrutura de um corpo é a composição de sua relação. E o que pode um corpo senão sua capacidade de tornar ativo todo movimento que o afeta, sua natureza e os limites do poder de ser afetado? Deus causa de todas as coisas assim como causa de si, tendo em si um poder de ser afetado de infinitas formas, poder esse infinitamente preenchido. Se ele é causa, essa afecção não é paixão, pois é produzida por ele próprio. Uma afecção só é paixão quando não for explicada pela natureza do corpo afetado. Portanto, afecções explicadas pela natureza do corpo afetado serão ativas, serão elas mesmas ações. Se deus causa de todas as suas afecções, todas as s afecções são explicadas pela sua natureza, portanto, são ações. Ao contrário, se o que acontece com os modos finitos é serem afetados por causas externas à sua natureza, todas as suas afecções são paixões, ou seja, são passivas. Podem os modos finitos chegar às afecções ativas? Segundo o autor, mesmo que ele consiga produzi-las enquanto existir, não suprimirá totalmente as paixões, apenas reduzirá a parte ocupada por elas. Toda afecção em forma de ideia da qual o indivíduo não é causa é inadequada, e as paixões decorrentes dela são paixões passivas. Quanto ao poder de ser afetado, ele permanece constante, independente de afecções ativas ou passivas. Se forem ativas, produzirá potência de agir, se passivas, potência de sofrer. À medida que uma aumenta, a outra diminui, então, se a capacidade para potência ativa aumentar, a passiva fatalmente diminuirá. 
Quanto à força ativa e passiva, o pensamento de Leibniz questiona, conforme observa Deleuze (1968) se força passiva é autônoma. A resposta é: "a força ativa é real por direito, afirmativa e positiva. A força passiva não afirma nada a não ser a imperfeição do finito; constitui simplesmente a limitação da força ativa". Para Espinosa potência de sofrer não exprime nada de positivo; toda a afecção passiva é baseada em um imaginário que a impede de ser real. $O$ indivíduo é passivo e apaixonado em razão da sua imperfeição, age pelo que tem, e é passivo pelo que não tem. Na verdade, sua potência de sofrer, sua servidão é o grau mais baixo de sua potência de agir.

A forma como as relações de potência circulam pelos modos, ou seja, permeadas por afecções vindas de fora, não condizentes com a natureza da essência, acabam por afastar o indivíduo dela e da sua potência de agir. A questão levantada por Espinosa se torna urgente: "Nem mesmo sabemos o que pode um corpo, ou seja: nem mesmo sabemos de que afecções somos capazes e até onde vai nossa potência" (ESPINOSA, 1973, p. 186).

Quanto mais o ser se aproxima do seu movimento único com natureza, entendendo-a como substância que contém em si a própria causa, mais pode produzir suas causas e sua potência de agir.

\section{O DESEJO COMO PRODUÇÃO}

Uma ideia central está em desenvolvimento tentando acompanhar a velocidade do pensamento de Gilles Deleuze, neste caso, voltada ao seu conceito de produção, especificamente ao conceito de desejo como produção. Usamos como veículo a expressão do corpo, sua potência, para tanto, percorremos primeiro a construção ontológica do filosofo, enfatizando a pura diferença, esta, que é interna onde 0 ser unívoco, porque transpassado pela imanência, difere-se em acontecimentos sem comparações externas, sem analogias. Distante de qualquer possibilidade de imagem representativa no outro, inicia um movimento que se afasta do negativo, da falta, para somar territórios. Ao pensar o corpo e sua potência, Deleuze tem em Espinosa sua inspiração, já que o filosofo holandês pensa o corpo e suas afecções, atribuindo ao homem uma possibilidade de ser livre na medida em que transforma em potência sua capacidade de reação. 
"A produção como processo excede todas as categorias ideais e forma um ciclo ao qual o desejo se relaciona como princípio imanente" (DELEUZE, 2010, p. 15). O corpo se expressa em multiplicidades, já que é definido ontologicamente por Deleuze, não por de sua capacidade endógena, substancial e predicada, mas pela sua propriedade de encontrar-se com outro corpo. Este pensamento vai ao encontro de Espinosa, para quem, ideia e corpo estão em um mesmo nível ontológico. A ideia só existe se existe o corpo, não há privilégio da razão sobre ele, este, é imanente ao pensamento.

O conceito de desejo como produção é um dos pontos importantes na filosofia da diferença, e, como já citado no início da pesquisa, se inaugurado especificamente ao escrever com Guattari o "Anti-Édipo", suas primeiras obras já anunciavam o pensamento que contém uma proposta independente das representações submersas às identidades. Segundo Roudinesco (2007), Deleuze supunha o desejo como um trabalho do inconsciente concebido em agenciamento de territórios e não reduzido a cena familiar, ou seja, a grande crítica a psicanálise ${ }^{5}$ se desdobrava no ponto da ofensiva contra o monumento mais psicologizado do edifício freudiano, o complexo de Édipo, que significaria uma máquina de normalizar a libido e criar um ideal familiarista retrógado. Ainda Roudinesco, traduz a tentativa dos autores do "Anti-Édipo" ante as estruturas simbólicas e significantes, substituí-las por uma conceitualidade polivalente capaz de traduzir a essência maquínica de um desejo plural. Deleuze amplia o conceito de desejo além das relações edipianas, regidas em nome do pai, para um desejo inscrito em nome da história, produtivo na imanência das máquinas desejantes nas grandes máquinas sociais.

A relação crítica de Deleuze com a psicanálise tem uma intima articulação com a ideia de desejo como produção. No entanto, existe uma razão para tal rejeição, que é a pretensão da psicanálise de ser um discurso único, com uma

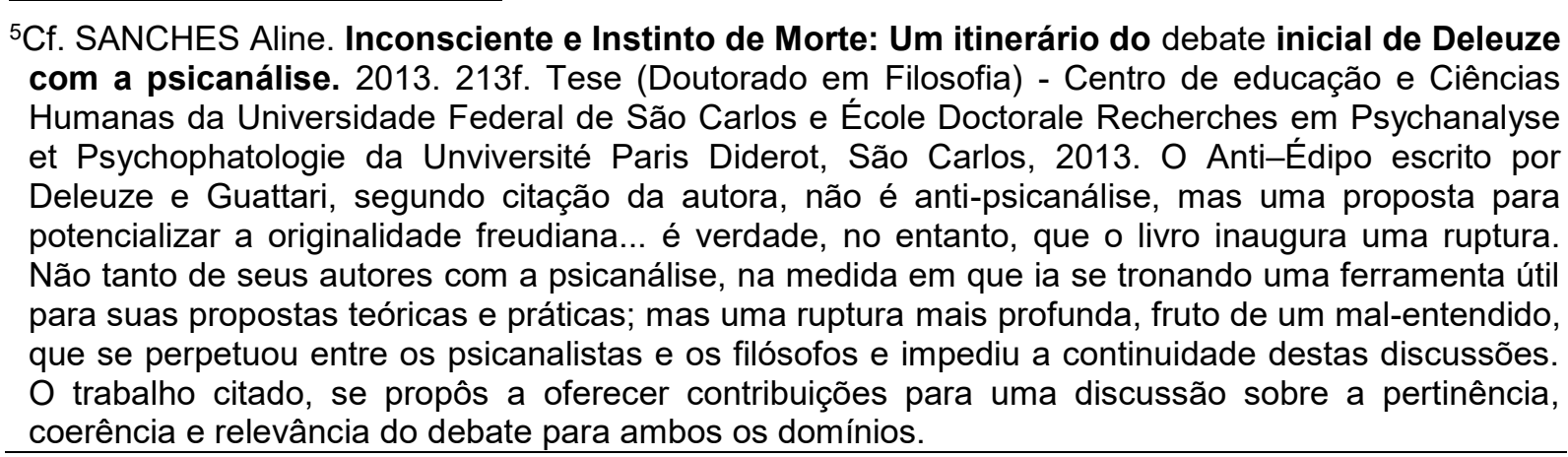


proposta única de "salvação". Escreve Deleuze: "Contra a psicanálise dissemos somente duas coisas: ela destrói todas as produções de desejo. Esmaga todas as formações de enunciados" (DELEUZE; PARNET, 1998, p. 93). A destruição do desejo se faz pela dinâmica de cultuar a lei e a falta, reduzir o inconsciente a algo negativo, detentor de fracassos e desejos perversos.

Deleuze liberta a relação sufocante do sujeito com um inconsciente habitado por fantasmas de subjetividades interpretativas, para transformá-lo em pura experimentação de produtividade.

Cabe salientar, que o desejo não é adquirir, se o vemos assim o colocamos como uma concepção idealista que o determina como falta. $O$ desejo, quando produz, o faz em uma concepção real, onde não existe o sujeito e seu objeto faltante, ambos constituem a mesma coisa. "O desejo é máquina, o objeto do desejo é também máquina conectada, de modo que o produto é extraído do produzir e algo se destaca do produzir passando ao produto. O ser objetivo do desejo é real em si mesmo" (DELEUZE; GUATARRI, 2010, p. 35).

Silva (2000), ao comentar sobre o Anti-Édipo o situa no contexto político de maio de 68. Deleuze e Guattari através da instauração de um novo conceito de desejo desvinculado da falta delineiam, segundo a autora, um novo traçado na história, retirando o desejo de sua articulação limitada ao sujeito e suas subjetividades, para lançá-lo no âmbito político e social. "Não se trata de o adaptar de o socializar, de o disciplinar, mas de o ligar de tal maneira que o seu processo não seja interrompido num corpo social e que produza enunciações coletivas" (DELEUZE, 2010, p. 337).

O conceito de desejo em Deleuze encerra a geografia articulada de sua ontologia. Seu aspecto de produção vem como experimento, em que a conexão de elementos se faz em movimento continuo, como cita Deleuze: "o desejo é um processo que descreve um plano de consistência, um campo de imanência, um corpo sem órgãos, percorrido de partículas e de fluxos que escapam tanto dos objetos como dos sujeitos" (DELEUZE; PERNET, 1998, p.105). 


\section{CONSIDERAÇÕES FINAIS}

Uma questão se fez presente durante o trajeto desse estudo: o que pode um corpo? Na medida em que foram estudados alguns dos elementos que habitam a construção ontológica de Deleuze, o ponto de interrogação transformou-se em proposta, porque em toda a articulação conceitual deste autor a produção é uma constante. Um corpo pode, porque deseja e esse desejo se afasta do negativo e da falta, na medida em que é desidentificado dos processos da representação. Esta afirmação contém três conceitos: negatividade, identidade e representação. Este movimento conceitual ocorre na medida em que a proposta ontológica de Deleuze se baseia não mais nos sujeitos identificados em seus egos, marcados pelos processos externos, cheios de subjetividades significantes, e sim no predicado, no vir a ser, naquilo que não cessa no sujeito, mas o transpassa. Entendemos a crítica à negatividade estudando a diferença, e esta, só pode acontecer porque está articulada a imanência e a univocidade do ser.

A pura diferença foi a primeira proposta de estudo nessa pesquisa. Para que pudéssemos entendê-la, a questão da transcendência foi um ponto de partida. Em Deleuze, assim como em Espinosa a transcendência não existe como conceito articulador do ser e de suas relações, seu campo é transformado em total espaço para a imanência. $O$ fato de existir, como já foi citado neste texto, já é um estatuto ontológico da univocidade. "O ser é unívoco", e contém em si toda a diferença, no entanto, esta é interna. É importante que esteja claro que, se a distribuição existe no ser unívoco, ela é diferente daquela que o divide baseada em fatores externos ditados por determinações, por domínios, por categorias. A distribuição que circula na univocidade é nômade, sem cercas, livre de toda identificação que a encerre em medidas ou territórios. Dentro da univocidade um território pode ser preenchido por várias manifestações do ser, o que é totalmente diferente de dividi-lo em sistemáticas formas ditadas, ora pela analogia, pela identidade, pela semelhança, ou pela oposição que são elementos da representação.

A multiplicidade é o acontecimento da diferença. Para que cheguemos a ela é importante agenciá-la com a noção de corpo. Se for baseada em suas características endógenas com seus limites de forma e circunstância, o teremos limitado ao seu espaço individual, mas se o considerarmos pela sua capacidade de 
afetar e ser afetado, então, ele existirá na medida desses encontros múltiplos e sua multiplicidade o representará ao infinito. A hierarquia que caracteriza o campo da transcendência e que é estabelecida pela maior ou menor distância do ser ideal, no ser unívoco se traduz em potência, não medida por degraus já predeterminados e sim por graus de potência ou intensidade. Um corpo existe pela sua capacidade de encontro com outros corpos, o que gera sua intensidade de produção e sua potência.

Espinosa é, entre outras características, o pensador da potência, da univocidade e da multiplicidade, ele que, no quinto livro de sua Ética, configura a experimentação do desejo como produção na medida em que lança o "método de invenção" e nele, a possibilidade de criação. São corpos não mais marcados por afecções, ou apenas conscientes de seus mecanismos de funcionamento e sim, totalmente capazes de realizarem seus próprios movimentos. Citamos Espinosa: "A felicidade não é o prêmio da virtude, mas a própria virtude, e não gozamos dela por refrearmos as paixões, mas ao contrário, gozamos dela por podermos refrear as paixões" (ESPINOSA, 1973, p. 306). Entendemos por paixões as marcas externas que produzem o corpo apaixonado, ou seja, tão perdido de seus próprios movimentos, que se faz incapaz do contentamento íntimo, da pura diferença ativa em território livre, onde as intensidades dos encontros acontecem em saltos, sobre as barreiras sedentárias da filosofia da representação.

O encontro estabelece um entre, no sentido de produção no espaço, não uma imitação, ou uma identificação e sim, uma ampliação móvel de um ir e vir de potências. Escrevemos já sobre um "devir revolucionário" o que suscita o aspecto político dessa questão, onde a proposta do encontro subtrai a estrutura interna que o define, ou seja, a institucionalização que o limita. Não desejo tal coisa porque algum referencial diz que é bom, ela se torna boa porque a desejo, porque a criação se faz em um movimento interno asignificante.

A produção do desejo veiculada como expressão do poder do corpo se apresenta no momento final da pesquisa, como continuidade. Os elementos que se constituíram em vivos agenciamentos conceituais, se enfileiram em abertura para novos pensares, novas intensidades, vindas da filosofia de Deleuze que se faz nômade. O movimento que se faz no mundo e que, inadvertidamente, poderia ser visto como comportamento operante, signo do tempo, reflexo do atual, é na verdade 
um campo de multiplicidades, a ser desvendado pela filosofia. Neste, como escreve Deleuze, "os círculos se retraem e o virtual se aproxima do atual para se distinguir dele cada vez menos" (DELEUZE; PERNET, 1998, p. 177). Em toda a diversidade dos universos de iniciações implicadas pelo que é explicito em atual, existe um processo virtual a ser revelado, e nele, toda a possibilidade de produção.

Aquilo que atravessa o corpo o reinventa e é desta infinita ausência de contornos que se potencializa o desejo.

\section{REFERÊNCIAS}

CRAIA, Eladio Constantino Pablo. Gilles Deleuze e a questão da técnica. 2003, 290 f. Tese (Doutorado em Filosofia) - Departamento de Filosofia do Instituto de Filosofia e Ciências Humanas, Universidade Estadual de Campinas, Campinas, 2003.

DELEUZE, Gilles. A ilha deserta: e outros textos. Edição preparada por David Lapoujade. Trad. Luiz B. L. Orlandi. São Paulo: Iluminuras, 2010.

. Diferença e repetição. Trad. Luiz Orlandi e Roberto Machado. 2. ed. São Paulo: Ed. Graal, 2009.

Espinosa e o problema da expressão. Trad. de A. Guérinot. Paris: Minuit, 1968. Disponível em: <www.webdeleuze.com/php/texte.php?cle= 194\&groupe=Spinoza>. Acesso em: 03 mar. 2014. 34, 2010.

; GUATARRI, Felix. O Anti-Édipo. Trad. Luiz B. L. Orlandi. São Paulo: Ed. ; Mil platôs: capitalismo e esquizofrenia. Trad. Ana Lúcia de Oliveira. São Paulo: Ed. 34, 2008, v. 3.

; PARNET, Claire. Diálogos. Trad. Eloísa Araujo Ribeiro. São Paulo: Ed Escuta, 1998.

ESPINOSA, Baruch de. Ética. São Paulo: Abril Cultural, 1973. (Coleção os Pensadores).

LARRAURI, Maite. El deseo. Segun Gilles Deleuze. Valencia: Tandem, 2000. 
. Espinosa e as Mulheres. Trad. Emanuel Ângelo da Rocha Fragoso. Revista de filosofia do mestrado acadêmico em filosofia da UECE, Fortaleza, v.3, n. 6, p 209-244, verão. 2006. Disponível em:<www.uece.br/ kalagatos/dmdocuments $>$. Acesso em: 17 abr. 2014.

MACHADO, Roberto. Deleuze, a arte e a filosofia. 2. ed. Rio de Janeiro: Zahar, 2010.

MIQUEU, Christophe. A negação da teologia e das causas finais. In: MARTINS, André. $\mathrm{O}$ mais potente dos afetos: Spinoza e Nietzsche. São Paulo: Martins Fontes, 2009.

ROUDINESCO, Elisabeth. Filósofos da tormenta. Canguilhem, Sartre, Foucault, Deleuze e Derrida. Trad. André Telles. Rio de Janeiro: Zahar, 2007.

SANCHES Aline. Inconsciente e Instinto de Morte: Um itinerário do debate inicial de Deleuze com a psicanálise. 2013. 213f. Tese (Doutorado em Filosofia) Centro de educação e Ciências Humanas da Universidade Federal de São Carlos e École Doctorale Recherches en Psychanalyse et Psychophatologie da Unviversité Paris Diderot, São Carlos, 2013.

SILVA, Cintia. Corpo e Pensamento: alianças conceituais entre Deleuze e Espinosa. 2007, 273f. Tese (Doutorado em Filosofia) - Departamento de Filosofia do Instituto de Filosofia e Ciências Humanas da Universidade Estadual de Campinas, Campinas, 2007.

O conceito de desejo na filosofia de Gilles Deleuze. 2000, $173 \mathrm{f}$. Dissertação (Mestrado em Filosofia) - Instituto de Filosofia e Ciências Humanas, Universidade Estadual de Campinas, Campinas, 2000.

Artigo recebido em: 16/10/2019

Artigo aprovado em: 18/10/2019

Artigo publicado em: 24/10/2019 